\title{
Correspondence
}

\section{A simple technique for photographing living microfilariae of Onchocerca volvulus in the anterior chamber of the eye}

TO THE EDITOR, British Journal of Ophthalmology

SIR, Living microfilariae in the anterior chamber of the eye are a common sign of ocular onchocerciasis, but so far there has been no known technique for photographing them. A microfilaria in the corneal stroma was photographed with a retroillumination technique by Brown (1971), but the living microfilariae in the anterior chamber present a problem because of their mobility. Sarkies (1951) observed that the microfilariae in the anterior chamber could be seen with an ophthalmoscope in the light reflected from the fundus.

It is possible to take photographs of the microfilariae in the anterior chamber with the fundus reflex as background and using a Kowa RC-2 camera. The media of the eye must be perfectly clear and the pupil well dilated. Also, the camera must be held in a position where the optic disc will be in line to give a luminous fundus reflex. The patient should have his head bent down before the examination, as described by Anderson and Fuglsang (1973), to make the maximum number of microfilariae

\section{Obituary}

F. T. Ridley, $M S c, M B, B S, F R C S$

Mr F. T. Ridley, formerly surgeon to Moorfields Eye Hospital, died on 2 February. He was 73.

Frederick Thomas Ridley was born in Birmingham and received his early education at King Edward's school. He graduated B.Sc. Birmingham in 1922 and proceeded M.B., B.S. London in 1925. He acquired the Fellowship of the Royal College of Surgeons in 1928.

In his early days at St Mary's Hospital he worked with Fleming on lysozyme and devised a method of purification and concentration. Later, after the discovery of penicillin by Fleming, Ridley's method was applied to this new substance, and he was the first to show that penicillin would go into solution in an organic solvent such as alcohol and that it was possible to get rid of inert and possibly toxic material in this way.

In 1948 he was appointed to Moorfields Eye Hospital from the Central Eye Hospital in Judd Street, where he was surgeon and one time pathologist. He set up at High Holborn the contact lens department, which became an active centre for research on the role of contact lenses in the

\section{Notes}

\section{Canadian Ophthalmological Society Calgary, 5-9 June}

The 40th annual meeting will be held at the Calgary Convention Centre in Calgary, Alberta, on 5-9 June. visible in the central anterior chamber close to the cornea. This facilitates focusing with the camera. The camera lens with magnification $\times 2$ was used at the closest possible distance from the eye. Exposure with Kodachrome 64 reversal film was made at intensity step 6 of the electronic flash.

The technique described above can be used under field conditions and is of interest for education purposes. Yours faithfully, B. THYLEFORS

Onchocerciasis Control Programme in the

Volta River Basin Area

OMS/OCP BP 549

Ouagadougou,

Upper Volta

\section{References}

Anderson, J., and Fuglsang, H. (1973). Transactions of the Royal Society of Tropical Medicine and Hygiene, 67, 544. Brown, N. (1971). British Journal of Ophthalmology, 55, 517. Sarkies, J. W. R. (1951). Lancet, 1, 1205.

treatment of eye disease. He was president of the Section of Ophthalmology at the Royal Society of Medicine in 1963, and he was honoured by the Middlemore lectureship in 1951, the Doyne memorial medal in 1954, the Edward Nettleship prize and gold medal in 1953, and the Sight Foundation Award of Baylor University in 1966.

Frederick Ridley had a scientific outlook with an attraction for mathematics. It was for this reason he found the problems of contact lenses a satisfactory challenge as they appealed to his sense of accuracy. Purely clinical problems with their essential doubts and their inevitable irrelevancies rarely evoked his enthusiasm. His delight was abstract discussion. As senior surgeon at Moorfields Eye Hospital, High Holborn, he made himself available to any member of the staff who was in difficulties or needed his help. He would readily champion a cause, especially if it were in danger of being lost, or an individual, particularly if there was a suggestion of deprivation of rights. In action his big-heartedness could always be relied upon, for beneath his philosophical musings he hid a kindly and considerate personality. $\mathrm{He}$ is survived by his wife, Pauline Cartier Bourgeois, and two daughters by his previous marriage, Diana and Sandra, and by two grandchildren.

The programme will include feature symposia on orbital diseases and on recent advances in ophthalmology, as well as 10 clinical workshops (a new departure) and selected free papers. Further information and registration forms from the Canadian Ophthalmological Society, PO Box 8650, Ottawa, Ontario K1G 0G8, Canada (tel. (613) 731-6493). 